\title{
Recurrent respiratory papillomatosis: clinical presentation, treatment modalities, and outcomes in Khartoum state
}

\author{
Khalid Mahmoud Sayed Seedahmed ${ }^{1 *} \mathbb{0}$, Abusufian Hassan El-Haj ${ }^{2}$ and Ahmed Mohammed Ahmed Bashir ${ }^{3}$
}

\begin{abstract}
Background: In this hospital-based cohort study, a total number of 52 patients with recurrent respiratory papillomatosis were studied. The medical histories of all the patients were taken and physical examination was conducted thoroughly. Types of surgeries were also observed and the sites of papillomatous lesions were identified. The patients then followed up after surgeries to assess the outcomes and to evaluate the satisfaction levels of the patients.

Result: There was obvious gender predilection toward male patients. Ninety percent of the cases were younger than 20 years old, and $50 \%$ of the cases were found to be in the group of 5-10 years old. The most predominant symptom that had been noticed in all of the patients was the change of voice. The study also found that around $46 \%$ of the patients had a history of surgical interventions as trials to treat the disease. Acyclovir tabs were prescribed for only 4 patients. No other forms of adjuvant therapies were prescribed. It is also showed that around $65.4 \%$ of the cases underwent surgical removal of the papillomata by debulking using cold steel. $30.8 \%$ underwent laser and two patients underwent coblation surgeries. Forty-two percent of the patients reported good and satisfactory outcomes with obvious relief from presenting symptoms and no apparent papilloma after IDL examination.
\end{abstract}

Conclusion: Recurrent respiratory papillomatosis presents with a highly variable clinical course in both juvenile and adult patients, with a spectrum from indolent to aggressive disease. But the severity of the condition is more among the younger ages. Change of voice was the first symptom in all of the cases. The use of adjuvant medical treatment in Sudan to treat respiratory papillomatosis is not a routine practice.

Keywords: RRP, JORRP, AORRP, Recurrent respiratory papillomatosis

\section{Background}

Recurrent respiratory papillomatosis is a rare and potentially life-threatening benign neoplasm caused by human papillomavirus (HPV). RRP is characterized by recurrent proliferation of the papillomata anywhere in the respiratory tract from the nasal vestibules to the terminal bronchi. Predominant sites are where there is a change of epithelium (e.g., from squamous to ciliated) and especially the tonsillar pillars, uvula, vocal folds, and laryngeal

\footnotetext{
*Correspondence: khalidmsayed@gmail.com

${ }^{1}$ Khartoum ENT Teaching Hospital - Sudanese Medical Specializations

Board, Khartoum, Sudan

Full list of author information is available at the end of the article
}

commissure. It can occur in both children and adults. The juvenile form is more frequent and more aggressive requiring repeated surgeries $[1,2]$.

\section{Etiology}

Human papillomavirus (HPV) was confirmed as the causative agent in RRP [1]. A study has revealed more than $180 \mathrm{HPV}$ genotypes, with specific affinity for squamous epithelial cells but different tissue preferences, resulting in various clinical presentations [3]. HPV has etiological associations with many benign and malignant tumors of the epidermal tissues. It is associated avidly with malignancies of the cervix and other anogenital tumors, such as carcinoma of the anus, penis, vulva, and vagina, as 
well as tumors of the head and neck region [4]. The subtypes of HPV are classified as being of high and low risk according to their potential for malignant transformation of epithelial cells $[4,5]$. Subtypes 6 and 11 are responsible for more than $90 \%$ of RRP cases $[3,6]$. Patients infected with type $11 \mathrm{HPV}$ develop more aggressive disease [6] which may lead to significant airway obstruction requiring frequent surgical procedures and adjuvant medical treatment, and sometimes even tracheostomy, to maintain airway patency [6]. Other subtypes, such as 16,18 , 31 , and 33, are also associated with RRP, although with a lower prevalence $[5,6]$. Subtypes 16 and 18 are considered to be high risk, with the higher potential for malignant transformation, particularly to squamous cell carcinoma, which occurs in less than $1 \%$ of juvenile RRP cases $[3,7,8]$.

Recurrent respiratory papillomatosis (RRP) appears grossly as sessile or pedunculated pinkish masses with fingerlike projections giving it the feature of irregular exophytic clusters. It is important for the surgeon to be meticulous when approaching the patients endoscopically as any injury to the healthy ciliated epithelium may catalyze its metaplasia to non-ciliated squamous epithelium which will lead to an iatrogenic squamo-ciliary junction which is considered as the favorite site for the offending virus to be implanted which may explain why RRP flourishes in patients with uncontrolled gastroesophageal reflux. Histologically, these fingerlike projections are of nonkeratinized stratified squamous epithelium laid over a vascularized connective tissue stoma. It is likely that the host immune system plays an integral role in the pathogenesis of HPV-induced lesions [9].

\section{Epidemiology}

RRP shows a characteristic bimodal distribution, affecting children and young adults. The juvenile form occurs in patients younger than 20 years of age. This form of the disease is generally more aggressive, with multiple papillomatous lesions, and has a high recurrence rate. The adult form develops after 20 years of age, in the third and fourth decades of life, more commonly in males. In this form, the papillomas are often solitary, with a high degree of inflammatory reactivity; they do not usually spread and recur less frequently than those seen in the juvenile form [7]. Malignant transformation has been reported in patients with RRP (less than $1 \%$ ), and the mechanism of such transformation is still under debate $[10,11]$.

\section{Transmission}

The exact mode of transmission of the virus remains unclear. There are many researches debating the likelihood of acquiring the infection through transmission of the virus from mothers with genital HPV infection to their babies $[12,13]$. Different studies observed a relation between adult-onset RRP and the oral-genital contact. It is also found that patients with AORRP were more likely to have had more sexual partners and oral sex than their controls. But, it is also confirmed that HPV has the capability to cause latent infections in the basal layer of otherwise healthy-appearing mucosa. These dormant foci may be reactivated later after vertical transmission of the virus to vaginally delivered children $[14,15]$.

The clinical presentation depends on the anatomical location of the papilloma. Common clinical symptoms include hoarseness of voice (voice changes in general), cough, wheezing, shortness of breath, choking, syncope, etc. The hallmark of RRP in juvenile cases is the triad of relentlessly progressive hoarseness of voice, stridor, and respiratory distress. Due to its non-specific clinical manifestations, RRP is easily misdiagnosed as asthma, acute laryngitis, upper respiratory infection, or bronchitis. It is strongly advised to warrant laryngoscopy in cases of children with symptoms of dysphonia and obstructive airway symptoms $[10,11]$.

\section{Management}

Nowadays, there is no available cure for this disease, and treatment is basically focused on maintaining airway patency and voice quality. Patients often require frequent surgeries and occasionally adjuvant therapy (interferon, Cidofovir, bevacizumab, Celecoxib, PD-1 inhibitor) when surgery is unable to control the disease.

Prevention via HPV vaccine is probably the most exciting advancement in RRP management. Three types of vaccines are already in use in many countries.

\section{Methods}

This is a prospective cohort hospital-based study. Fiftytwo cases of RRP were enrolled in the study from different hospitals in Khartoum state. Their clinical histories were thoroughly taken and studied to assess the patterns of the clinical presentations and the types of the opted medical and surgical therapies. All of the patients were assessed preoperatively by indirect laryngoscopy to assess the extension of the lesions, and later biopsies were taken to confirm the diagnosis histopathologically. Three types of surgical interventions were observed, including conventional debulking by cold steel, laser surgery, and coblation. The patients were observed and followed up for a period of 2 months to assess their levels of satisfaction and the outcomes after surgical interventions. A second indirect laryngoscopy was done for all of the participants postoperatively to evaluate the anatomic effects of the surgeries including the mobility of the vocal cords and the patency of the airways. Questionnaires and 
data sheaths were used to document the progress of the condition pre/postoperatively. The voice quality in each patient was checked roughly depending on the feedbacks from the treating physicians and the patients. The authors did not use the specific voice analysis tool to analyze the qualities of the voices.

\section{Results}

Fifty-two patients were enrolled in this study. Among them, $61.5 \%$ are males and $38.5 \%$ are females. Eightysix percent of the cases were younger than 20 years old. Fifty percent of the cases were found to be in the group of 5-10 years old. Almost $23 \%$ of the cases were between 10 and 20 years old. Only $13.5 \%$ of the participants were younger than 5 years old and $13.4 \%$ of them were older than 20 years old (Fig. 1).

The first presenting symptom in $52 \%$ of the patients was a change of voice, and the remainders reported extra symptoms besides a change of voice such as cough and SOB. Although all of the cases reported that they had suffered from a change of voice in the early stage of the disease, even though $48 \%$ of them did not seek medical advice until they developed other symptoms such as shortness of breath and cough.

It is found that around $46.2 \%$ of the cases had suffered from the presenting symptoms for more than 1 year and $29 \%$ of them had the symptoms for a period of 3-6 months. Almost $9.5 \%$ of the patients had experienced the symptoms for 2 months only. $7.7 \%$ of the cases reported the symptoms for 1 month only and an equal proportion of patients suffered from the symptoms for 6-12 months. At the time of presentation, around $65 \%$ of the cases did not experience stridor and the remainder 35\% suffered from variable degrees of stridor.

Forty percent of the enrolled cases underwent tracheostomy to secure the threatened upper airway patency. All of the patients were decannulated after surgical intervention.

Almost $46 \%$ of the cases have a history of operation for treatment of papillomatosis. Fifty-four percent of the case reported no history of the surgical trial.

Around $63.4 \%$ of the cases $(n=33)$ received no medical treatment neither preoperatively nor postoperatively. Almost $28.8 \%$ of them $(n=15)$ received steroid intraoperatively and postoperatively. Only four cases received a course of acyclovir after operation.

Around $65.4 \%$ of the cases underwent surgical removal of the papillomas by debulking using cold steel. 30.8\% underwent laser surgeries and two patients underwent coblation surgeries.

In $75 \%$ of the cases, the papillomata were confined in the glottic area. $13.4 \%$ of the cases were found to have subglottic papilloma. 9.6\% of them had papillomatous lesions traversing transglotticaly. One patient was found to have supraglottic papilloma (Table 1).

After 2 months of follow-up, from a total of 34 patients who underwent conventional debulking surgeries, 26.5\% reported good outcomes with obvious and dramatic relief of the presenting symptoms and no apparent papilloma after IDL examination. $20.6 \%$ of these patients reported to be satisfied with the outcome with an obvious improvement of the symptoms they were not compliant to go for IDL. $38.2 \%$ (23) reported partial satisfaction with an obvious change in the quality of the voice. Of 16

\section{Frequency distribution of the cases according to age}

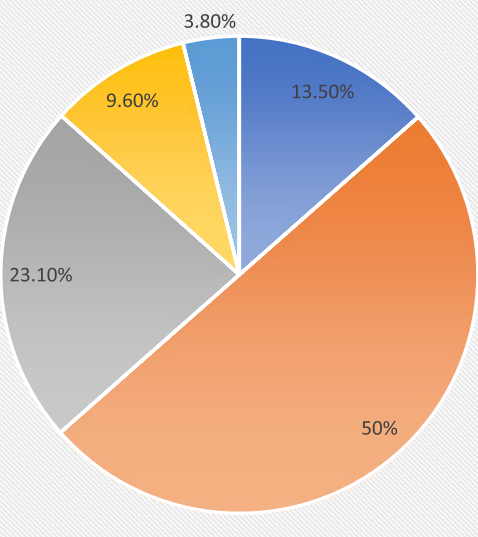

- less than 5 Years

- 5 - 10 years

- 10 - 20 years

20 - 35 years

more than 35 years

Fig. 1 Frequency distribution of the cases according to age 
Table 1 Frequency distribution of the cases according to sites of the papilloma found intraoperatively

\begin{tabular}{llllll}
\hline & Frequency & $\%$ & Valid percent & Cumulative percent \\
\hline Valid & Glottic & 39 & 75.0 & 75.0 & 75.0 \\
& Supraglottic & 1 & 1.9 & 1.9 & 76.9 \\
Subglottic & 7 & 13.5 & 13.5 & 90.4 \\
& Transglottic & 5 & 9.6 & 9.6 & 100.0 \\
& Total & 52 & 100.0 & 100.0 & \\
\hline
\end{tabular}

patients who underwent laser surgeries, $18.8 \%$ reported good outcomes with obvious and dramatic relief of the presenting symptoms and no apparent papilloma after IDL examination. $12.4 \%$ of these patients reported to be satisfied with the symptoms they were not compliant to go for IDL. 43.8\% reported partial satisfaction with an obvious change in the quality of the voice (Table 2). Of 39 cases with glottic papilloma, 38\% reported good and satisfactory outcomes with $46.2 \%$ reporting partial satisfaction. Of 7 cases with subglottic papilloma, 57.2\% reported good and satisfactory outcomes with only 2 patients reporting partial satisfaction. Sixty percent of the patients ( 3 out of 5 patients) with transglottic lesions reported good outcome (Table 3).

\section{Discussion}

Demographically, there was obvious gender predilection toward male patients with a male to female ratio of 1.6:1. The result was close to the study conducted by Adoga et al. and Armstrong et al. [16, 17].

Age-specific prevalence: $90 \%$ of the cases were younger than 20 years old and $50 \%$ of the cases were found to be in the group of 5-10 years old. Armstrong et al. and
James et al. also concluded that RRP is more common in children than in adults $[17,18]$.

The most predominant and first symptom that had been noticed by all the patients was the change of voice. Other associated symptoms such as cough and SOB were reported in only $48 \%$ of the cases. This is also concluded in the study conducted by M. James et al. [19].

In this study, only $35 \%$ of the cases had suffered from stridor which mandated the treating doctor to secure the airways by doing tracheostomies. The rate was higher in the study conducted by Adoga et al. (96\%). He also concluded that tracheostomy cannot be avoided in cases of severe stridor [16].

The study also found that around $46 \%$ of the patients had a history of surgical interventions as trials to treat RRP. Derkay et al. found that all of their patients, who were under 3 years old, needed to go for surgery in a rate of 4.4 procedures per year [9].

The study found that only $30 \%$ of the cases had received medical treatment in form of steroids with only one patient receiving acyclovir tabs postoperatively with no obvious indication. Ivancic et al. conducted a survey that indicated that surgeons typically consider adjuvant therapy in patients getting surgery

Table 2 Frequency distribution of the cases according to the type of surgery in relation to the outcome

\begin{tabular}{|c|c|c|c|c|c|c|c|}
\hline & & & Good Outcome & $\begin{array}{l}\text { Satisfactory } \\
\text { Outcome }\end{array}$ & $\begin{array}{l}\text { Partially } \\
\text { Satisfactory } \\
\text { Outcome }\end{array}$ & Missed & Total \\
\hline \multirow[t]{8}{*}{ Type of Surgery } & \multirow{2}{*}{$\begin{array}{l}\text { Conventional } \\
\text { Cold Steel }\end{array}$} & Count & 9 & 7 & 13 & 5 & 34 \\
\hline & & $\begin{array}{l}\% \text { Within type of } \\
\text { surgery }\end{array}$ & $26.5 \%$ & $20.6 \%$ & $38.2 \%$ & $14.7 \%$ & $100.0 \%$ \\
\hline & \multirow[t]{2}{*}{ Laser } & Count & 3 & 2 & 7 & 4 & 16 \\
\hline & & $\begin{array}{l}\% \text { Within type of } \\
\text { surgery }\end{array}$ & $18.8 \%$ & $12.4 \%$ & $43.8 \%$ & $25.0 \%$ & $100.0 \%$ \\
\hline & \multirow[t]{2}{*}{ Coblation } & Count & 0 & 1 & 1 & 0 & 2 \\
\hline & & $\begin{array}{l}\% \text { Within type of } \\
\text { surgery }\end{array}$ & $0.0 \%$ & $50.0 \%$ & $50.0 \%$ & $0.0 \%$ & $100.0 \%$ \\
\hline & \multirow[t]{2}{*}{ Total } & Count & 12 & 10 & 21 & 9 & 52 \\
\hline & & $\begin{array}{l}\text { \% Within type of } \\
\text { surgery }\end{array}$ & $23.1 \%$ & $19.2 \%$ & $40.4 \%$ & $17.3 \%$ & $100.0 \%$ \\
\hline
\end{tabular}


Table 3 Frequency distribution of the cases according to sites of the papilloma in relation to the outcome

\begin{tabular}{|c|c|c|c|c|c|c|}
\hline & & Good Outcome & $\begin{array}{l}\text { Satisfactory } \\
\text { Outcome }\end{array}$ & $\begin{array}{l}\text { Partially } \\
\text { Satisfactory } \\
\text { Outcome }\end{array}$ & Missed & Total \\
\hline \multirow[t]{2}{*}{ Glottic } & Count & 6 & 9 & 18 & 6 & 39 \\
\hline & $\begin{array}{l}\% \text { Within site of papil- } \\
\text { loma }\end{array}$ & $15.4 \%$ & $23.0 \%$ & $46.2 \%$ & $15.4 \%$ & $100.0 \%$ \\
\hline \multirow[t]{2}{*}{ Supraglottic } & Count & 0 & 0 & 0 & 1 & 1 \\
\hline & $\begin{array}{l}\% \text { Within site of papil- } \\
\text { loma }\end{array}$ & $0.0 \%$ & $0.0 \%$ & $0.0 \%$ & $100.0 \%$ & $100.0 \%$ \\
\hline \multirow[t]{2}{*}{ Subglottic } & Count & 3 & 1 & 2 & 1 & 7 \\
\hline & $\begin{array}{l}\% \text { Within site of papil- } \\
\text { loma }\end{array}$ & $42.9 \%$ & $14.3 \%$ & $28.6 \%$ & $14.2 \%$ & $100.0 \%$ \\
\hline \multirow[t]{2}{*}{ Transglottic } & Count & 3 & 0 & 1 & 1 & 5 \\
\hline & $\begin{array}{l}\text { \% Within site of papil- } \\
\text { loma }\end{array}$ & $60.0 \%$ & $0.0 \%$ & $20.0 \%$ & $20.0 \%$ & $100.0 \%$ \\
\hline \multirow[t]{2}{*}{ Total } & Count & 12 & 10 & 21 & 9 & 52 \\
\hline & $\begin{array}{l}\% \text { Within site of papil- } \\
\text { loma }\end{array}$ & $23.1 \%$ & $19.2 \%$ & $40.4 \%$ & $17.3 \%$ & $100.0 \%$ \\
\hline
\end{tabular}

more than 3-4 times per year, but actual indications are not well-defined [20].

This study also showed that around $65.4 \%$ of the cases underwent surgical removal of the papillomata by debulking using cold steel. 30.8\% underwent laser and two patients underwent coblation surgeries. Shigeyuki Murono et al. observed a trend toward a preference for lasers rather than a microdebrider or cold instruments. Adoga et al. concluded that conventional endoscopic surgical excision is a safe technique [16, 21].

In our study in $75 \%$ of the cases, the papillomas were confined to the glottic area. Adoga et al. concluded that the most common site of lesions is the vocal cords in $55.2 \%[16]$.

After 2 months of follow-up, $42 \%$ of the patientreported good and satisfactory outcome with obvious relief from the presenting symptoms and no apparent papilloma after IDL examination. All of the reviewed studies had assessed the efficacy of surgical intervention combined with adjuvant medical treatment with no available study for evaluation of the efficacy of solely surgical treatment. Sandipta Metra et al. concluded that the mean interval of the symptom-free period since last surgery with acyclovir as an adjuvant was 13.5 months. Thus, surgery combined with acyclovir may postpone the need for repeating surgeries by prolonging the symptom-free periods [22].

\section{Conclusions}

- Recurrent respiratory papillomatosis presents with a highly variable clinical course in both juvenile and adult patients, with a spectrum from indolent to aggressive disease. But the severity of the condition is more among the younger ages with gender predilection toward males. The male to female ratio is $1.6: 1.0$.

- Change of voice could be the first and only symptom for almost all the cases.

- A large proportion of cases presented lately after more than 12 months from the start of the symptoms which definitely worsens the prognosis.

- The nature of the diseases itself entitles recurrency, so the aim of the surgeon may be better to increase the symptom-free period between the surgeries.

- Although it is not preferable to tracheostomize RRP cases, but the severity of the upper airway obstruction may dictate prioritizing the security of the airways over any other considerations. Many literatures advise not to tracheostomize such patients in fear of distal expansion of the disease and stomal recurrency.

- The use of adjuvant medical treatment in Sudan to treat RRP is not a routine practice, although some researches had come up with promising results in favor of using many kinds of adjuvant therapies.

- There is no significant difference in the outcomes between the two main types of treatment.

- There is no documented malignant transformation in the patients enrolled in this study.

\section{Acknowledgements}

The author is pleased to acknowledge Mr. Abusofian H. El-Haj (consultant otolaryngologist) who provided clinical feedback on the research and Mr. Ahmed Bashir (consultant otolaryngologist) who provided guidance and 
support throughout the work (Permission to acknowledge was taken from both).

\section{Authors' contributions}

K.M. wrote the introduction, searched the related published studies, collected the data and analyzed it, and wrote the conclusions and the recommendations. A. H. revised the introduction and the analysis and he was a major contributor in writing the manuscript. A. B. revised the analysis and contributed in the discussion and the conclusion. All authors read and approved the final manuscript.

\section{Funding}

No funding.

\section{Availability of data and materials}

Available on demand in the form of an SPSS file.

\section{Declarations}

\section{Ethics approval and consent to participate}

Written approval had been gained from the ethical committee at the research unit (EDC) in the Sudan Medical Specialization board. Written permission had been obtained from the administrative authority of otolaryngology in Khartoum state hospitals. Study data/information was used for the research purpose only. Informed written consents were taken from all the patients (or one of their parents in case of children younger than 16 years old) to participate in this study. The confidentiality issue was intentionally considered. The participation was voluntary. Any participant has had the right to withdraw at any stage.

\section{Consent for publication}

Not applicable (no individual personal data included).

\section{Competing interests}

The authors declare that they have no competing interests.

\section{Author details}

${ }^{1}$ Khartoum ENT Teaching Hospital - Sudanese Medical Specializations Board, Khartoum, Sudan. ${ }^{2}$ College of Medicine, Al Neilain University, Khartoum, Sudan. ${ }^{3}$ Doha ENT Specialized Hospital, Khartoum, Sudan.

Received: 9 September 2021 Accepted: 12 February 2022 Published online: 07 March 2022

\section{References}

1. Larson DA, Derkay CS (2010) Epidemiology of recurrent respiratory papillomatosis. Apmis. 118(6-7):450-454. https://doi.org/10.1111/j.1600-0463. 2010.02619.x

2. Watkinson JC, Clarke RW (2019) Scott-Brow's otorhinolararyngology head \& neck surgery - Vol 2 - pediatrics, ear and skull base, 8th edn. CRC Press Taylor \& Francis

3. Fusconi M, Grasso M (2014) Recurrent respiratory papillomatosis by HPV review of the literature and update on the use of cidofovir. Acta Otorhinolaryngol Ital 34:375-381

4. Donne AJ, Hampson L, Homer JJ, Hampson IN (2010) The role of HPV type in recurrent respiratory papillomatosis. Int J Pediatr Otorhinolaryngol 74(1):7-14. https://doi.org/10.1016/j.ijporl.2009.09.004

5. Carifi M, Napolitano D, Morandi M, Dall'Olio D (2015) Recurrent respiratory papillomatosis: current and future perspectives. Ther Clin Risk Manag 11:731-738. https://doi.org/10.2147/TCRM.S81825

6. Katsenos S, Becker HD (2011) Papillomatosis: a rare chronic disease, difficult to treat, with potential to lung cancer transformation: apropos of two cases and a brief literature review, pp 162-171. https://doi.org/10.1159/ 000327094 Published online

7. Fortes HR, von Ranke FM, Escuissato DL et al (2017) Recurrent respiratory papillomatosis: a state-of-the-art review. Respir Med 126:116-121. https://doi.org/10.1016/j.rmed.2017.03.030
8. Goon P, Sonnex C, Jani P, Stanley M, Sudhoff H (2008) Recurrent respiratory papillomatosis: an overview of current thinking and treatment. Eur Arch Oto-Rhino-Laryngology 265(2):147-151. https://doi.org/10.1007/ s00405-007-0546-z

9. Derkay CS, Bluher AE (2019) Update on recurrent respiratory papillomatosis. Otolaryngol Clin N Am 52(4):669-679. https://doi.org/10.1016/j.otc. 2019.03.011

10. Campisi P (2017) Recurrent respiratory papillomatosis. Recurr Respir PapilIomatosis July:1-196. https://doi.org/10.1007/978-3-319-63823-2

11. Omland T, Akre H, Lie KA, Jebsen P, Sandvik L (2014) Risk factors for aggressive recurrent respiratory papillomatosis in adults and juveniles. PLoS One:1-13. https://doi.org/10.1371/journal.pone.0113584 Published online

12. Puranen M, Yliskoski M (1981) Vertical transmission of human papillomavirus from infected mothers to their newborn babies and persistence of the virus in childhood. Published online

13. Tseng CJ, Liang CC, Soong YK, Pao CC (1998) Perinatal transmission of human papillomavirus in infants: relationship between infection rate and mode of delivery. Obstet Gynecol. 91(1):92-6. https://doi.org/10.1016/ s0029-7844(97)00593-0

14. Steinberg BM, Topp CW, Schneider PS, Abramson Allan L (1983) Laryngeal papilloma virus infection during clinical remission. N Engl J Med 308(21):1261-1264

15. Aaltonen $L$, Rihkanen $H$, Vaheri A, Papillomavirus $H$ (2002) Human papillomavirus in larynx. Laryngoscope. April:700-707

16. Adoga AA, Adoga SA (2008) Recurrent respiratory papillomatosis in Jos, Nigeria: Clinical presentation, management and outcome. East Cent African J Surg. 13(2):105-108. https://doi.org/10.4314/ecajs.v13i2

17. Armstrong LR, Derkay CS, Reeves WC (2017) Initial results from the national registry for juvenile-onset recurrent respiratory papillomatosis. Am Med Assoc 125(July 1999):743-748

18. Allen CT, Lee S, Norberg SM et al (2019) Safety and clinical activity of PD-L1 blockade in patients with aggressive recurrent respiratory papillomatosis. J Immunother Cancer 3:1-9

19. James M, Katundu D, Chussi D, Shija P (2018) Prevalence, clinical presentations, associated risk factors and recurrence of laryngeal papillomatosis among inpatients attended at a tertiary Hospital in Northern zone Tanzania. Pan African Med J 8688:1-7. https://doi.org/10.11604/pamj.2018.30. 209.11211

20. Ivancic R, labal H, deSilva B, Pan Q, Matrka L (2018) Current and future management of recurrent respiratory papillomatosis. Laryngoscope Investig Otolaryngol 3(1):22-34. https://doi.org/10.1002/lio2.132

21. Murono S, Nakanishi Y, Tsuji A et al (2014) Trends in the management of recurrent respiratory papillomatosis in Japan. Auris Nasus Larynx 2013:2013-2015. https://doi.org/10.1016/j.anl.2014.10.006

22. Mitra S, Das A, Ghosh D, Sengupta A (2019) Postoperative systemic acyclovir in juvenile-onset recurrent respiratory papillomatosis: the outcome:4-7. https://doi.org/10.1177/0145561318823311 Published online

\section{Publisher's Note}

Springer Nature remains neutral with regard to jurisdictional claims in published maps and institutional affiliations. 